\title{
Some Effects of Oxygen on the Physiology of Selenomonas ruminantium WPL 151/1 Grown in Continuous Culture
}

\author{
By OTHMAN ABDUL SAMAH† AND J. W. T. WIMPENNY* \\ Department of Microbiology, University College, Newport Road, \\ Cardiff CF2 ITA, U.K.
}

(Received 25 March 1981; revised 23 June 1981)

\begin{abstract}
Selenomonas ruminantium WPL $151 / 1$ was grown in continuous culture anaerobically and at different gas phase partial pressures of oxygen $\left(\mathrm{pO}_{2}\right)$. Low $\mathrm{pO}_{2}$ values led to substantial increases in whole-cell potential oxygen consumption rates and in NADH oxidase and superoxide dismutase activities in cell extracts. At the same time, concentrations of certain cytochrome pigments fell whilst lactate and acetate concentrations increased in the culture. As the $\mathrm{pO}_{2}$ was increased, growth yield became progressively lower, culture $E_{\mathrm{h}}$ became more positive and respiratory activity and NADH oxidase and superoxide dismutase activities fell. At these $\mathrm{pO}_{2}$ values cytochrome concentrations increased and fermentation products became more oxidized. Above a gas phase $\mathrm{pO}_{2}$ of $36.7 \mathrm{~mm} \mathrm{Hg}$ the culture began to wash out of the vessel. It is concluded that NADH oxidase and superoxide dismutase play an important part in protecting $S$. ruminantium against oxygen toxicity.
\end{abstract}

\section{IN TRODUCTION}

The presence of molecular oxygen inhibits the growth of obligate anaerobes. The gas has a toxic and often lethal effect whose physiological basis is not fully understood (Morris, 1970). Oxygen toxicity may be dependent on changes in redox potential $\left(E_{\mathrm{h}}\right)$ (Onderdonk et al., 1976), or due to the inactivation of key intracellular components or to the production of toxic compounds inside (Morris, 1975, 1976) or outside the cell (Frölander \& Carlsson, 1977). Preliminary studies with batch cultures of $S$. ruminantium 17 grown in a glucose-containing medium demonstrated the ability of this organism to survive considerable changes in oxygen tension (Wimpenny \& Samah, 1978). That this organism was able to tolerate some oxygen agrees with reports concerning strains of strictly anaerobic intestinal bacteria (Uesugi \& Yajima, 1978; Hoshino et al., 1978). Adaptation to oxygen may be related to an increase in NADH oxidase (O'Brien \& Morris, 1971; Ashley \& Shoesmith, 1977; Wimpenny \& Samah, 1978 ) and/or to a rise in superoxide dismutase activity (Ashley \& Shoesmith, 1977; Tally et al., 1977, Wimpenny \& Samah, 1978).

The present paper describes the influence of oxygen on the growth and metabolism of $S$. ruminantium WPL 151/1 grown in continuous culture. The effects of oxygen on oxygen uptake rates, cell yield, NADH oxidase and superoxide dismutase activities, cytochrome concentrations and fatty acid formation are reported and discussed.

\section{METHODS}

Organism. Selenomonas ruminantium strain WPL 151/1 was obtained from the culture collection of the Rowett Research Institute, Aberdeen. Bacteria were grown in a medium containing the following ( $\mathrm{g}^{-1}$ ): Bacto-Casitone

† Present address: Department of Biochemistry and Microbiology, University of Agriculture Malaysia, Serdang, Selangor, Malaysia. 
(Difco), 10; yeast extract (Oxoid), 2.5; $\mathrm{K}_{2} \mathrm{HPO}_{4}, 3 ; \mathrm{KH}_{2} \mathrm{PO}_{4}, 3 ;\left(\mathrm{NH}_{4}\right)_{2} \mathrm{SO}_{4}, 6 ; \mathrm{NaCl}, 6 ; \mathrm{CaCl}_{2}, 0 \cdot 6 ;$ $\mathrm{MgSO}_{4} \cdot 7 \mathrm{H}_{2} \mathrm{O}, 0 \cdot 6$; resazurin, $0 \cdot 1$. Reducing and vitamin solutions, containing (g per $100 \mathrm{ml}$ ): glucose, 6: $\mathrm{NaHCO}_{3}, 4 ; \mathrm{Na}_{2} \mathrm{~S}, 2 \cdot 5 ; \mathrm{Na}_{2} \mathrm{~S}_{2} \mathrm{O}_{4}, 2 \cdot 5$, and (mg per $100 \mathrm{ml}$ ): $p$-aminobenzoic acid, 0.01: biotin, 0.005; vitamin $\mathrm{B}_{12}, 0.005$, respectively, were sterilized separately by filtration and added in $100 \mathrm{ml}$ amounts to each litre of medium.

Growth conditions. Chemostat cultures of $S$. ruminantium WPL 151/1 (1.21) were grown in a modified CC 1500 laboratory fermenter (L. H. Engineering Co., Stoke Poges, Bucks.). The fermenter was equipped with a magnetically coupled agitator, automatic temperature control, and electrodes for measuring $E_{h}, \mathrm{pH}$ and dissolved oxygen tensions. The fermentation vessel and nutrient reservoir were kept under a constant flow $\left(100 \mathrm{ml} \mathrm{min}^{-1}\right) \mathrm{of}^{-}$ $\mathrm{CO}_{2}$ which had been passed through a heated column containing copper turnings to remove traces of oxygen. Growth was initiated by adding $5 \mathrm{ml}$ of an overnight culture of $S$. ruminantium WPL $151 / 1$ to the fermentation vessel. Batch culture growth continued for $24 \mathrm{~h}$ at $37^{\circ} \mathrm{C}$. Medium flow was then initiated to give a dilution rate of $0.03 \mathrm{~h}^{-1}$. The culture was maintained at $\mathrm{pH} 6.3$ and stirred at $200 \mathrm{rev} . \mathrm{min}^{-1}$. All investigations were made after the establishment of a stable population confirmed by turbidity measurements. The culture was exposed to different partial pressures of oxygen by injecting air into the gas stream and allowed to establish a new steady rate by incubation for at least $48 \mathrm{~h}$. Samples were collected in an ice-cold receiver for the measurement of oxygen uptake rates, cell yield and enzyme activities, and for the determination of cytochromes and the analysis of products. The purity of the culture was checked daily by removing samples and plating on nutrient agar (Difco). Plates were incubated at $37^{\circ} \mathrm{C}$ for $48 \mathrm{~h}$ aerobically or anaerobically.

Oxygen uptake measurements. Cells were harvested from $200 \mathrm{ml}$ of culture under anaerobic conditions by centrifugation at $10000 \mathrm{~g}$ for $10 \mathrm{~min}$. They were washed twice with ice-cold $20 \mathrm{~mm}$-potassium phosphate buffer (pH 7.0) and resuspended in about $7 \mathrm{ml}$ of the same buffer. Cells were processed and stored under anaerobic conditions for the duration of the experiment. Oxygen uptake rate was determined with an oxygen electrode (Rank Electrodes, Bottisham, Cambs.) at $37^{\circ} \mathrm{C}$. Glucose $(5 \mu \mathrm{mol})$ was added to the vessel after endogenous oxygen uptake rates had been determined.

Cell yield. The turbidity of samples was measured against a water blank at $550 \mathrm{~nm}$ using an MSE Spectroplus spectrophotometer and dry weights were determined from a standard calibration curve.

$E_{\mathrm{h}}$ measurement. The $E_{\mathrm{h}}$ value of the culture medium was measured using a bare platinum electrode together with a calomel reference electrode. Both electrodes were attached to a Vibron electrometer model 33B-2 (Electronic Instruments, Richmond, Surrey). The actual $E_{\mathrm{h}}$ value was obtained by subtracting the standard value of the calomel electrode $(247 \mathrm{mV})$ from all the observed values.

Enzyme activities. Two litres of culture sample were collected in an ice-cold receiving flask. The bacteria were harvested by centrifugation at $10000 \mathrm{~g}$ for $10 \mathrm{~min}$ and the pellet was washed twice with $10 \mathrm{vol} 20 \mathrm{~mm}$-phosphate buffer (pH 7.0) before being disrupted in a Hughes press (Hughes, 1951) cooled to $-30^{\circ} \mathrm{C}$ with dry ice. The crude broken material was centrifuged first at $34000 \mathrm{~g}$ for $20 \mathrm{~min}$ and then at $140000 \mathrm{~g}$ for $60 \mathrm{~min}$ to give particulate fractions and a substantially particle-free supernatant. No attempt was made to exclude air from the samples. NADH oxidase was assayed in a Pye Unicam SP 1800 spectrophotometer by following the oxidation of 50 $\mu \mathrm{M}-\mathrm{NADH}$ at $340 \mathrm{~nm}$ in $20 \mathrm{~mm}$-potassium phosphate buffer ( $\mathrm{pH} 7.4$ ). NADH peroxidase activity was examined by adding $50 \mu \mathrm{l} 0.1 \mathrm{M}-\mathrm{H}_{2} \mathrm{O}_{2}$ near the end of the NADH oxidase assay. The total assay volume was $3 \mathrm{ml}$. Superoxide dismutase was assayed by the method of Beauchamp \& Fridovich (1971) except that methionine was replaced by $100 \mathrm{~mm}$-ethylenediaminetetra-acetate. The $\mathrm{pH}$ of the assay mixture was maintained at $7 \cdot 8$. Different portions of each soluble fraction were tested and the degree of inhibition of nitroblue tetrazolium reduction relative to that in a control cuvette was plotted against protein concentration. The activity was expressed as the reciprocal of the amount of protein required to give $50 \%$ inhibition.

Determination of cytochrome spectra. Cells were harvested from $300 \mathrm{ml}$ of culture by centrifugation at $10000 \mathrm{~g}$ for $10 \mathrm{~min}$ and were washed twice in $20 \mathrm{mM}$-potassium phosphate buffer $(\mathrm{pH} \mathrm{7.0)}$. The cells were resuspended in $5 \mathrm{ml}$ of the same buffer and were maintained under anaerobic conditions over the period of the experiments. Room temperature spectra of whole-cell suspensions were determined in a Cary 14 spectrophotometer (Applied Physics Corp., Monrovia, Calif., U.S.A.). Difference spectra were determined on untreated samples or on samples reduced with dithionite versus samples oxidized with either fumarate or ferricyanide. A reduced sample was gassed for $60 \mathrm{~s}$ with carbon monoxide and the $\mathrm{CO}$-reduced versus reduced difference spectrum was recorded. Measurements of cytochrome concentrations were made using the following wavelength pair molar absorption coefficients: cytochrome $b, 562-570 \mathrm{~nm}, \varepsilon=19 \times 10^{3} \mathrm{M}^{-1} \mathrm{~cm}^{-1}$ (Ohnishi et al., 1967); cytochrome o, 529-417 nm, $\varepsilon=170 \times 10^{3} \mathrm{M}^{-1} \mathrm{~cm}^{-1}$ (Daniel, 1970).

Assay of fermentation products. Volatile and non-volatile fatty acids were determined in samples of the culture supernatant by gas-liquid chromatography using a Pye 104 series chromatograph fitted with a flame-ionization detector. The acids were separated using a glass column $(6 \mathrm{ft} \times 0.5 \mathrm{in})$ packed with $5 \%$ FFAP on Chromosorb G, with argon as carrier gas. The temperature was programmed isothermally at $180^{\circ} \mathrm{C}$. For volatile fatty acid determination $1 \mathrm{~g} \mathrm{NaCl}$ was dissolved in $4 \mathrm{ml}$ culture supernatant and the $\mathrm{pH}$ of the mixture brought down to 2 , before extraction with $1 \mathrm{ml}$ diethyl ether; $3 \mu \mathrm{l}$ samples were injected on to the column. For the determination of 
non-volatile acids, $1 \mathrm{ml}$ culture supernatant was mixed with $1 \mathrm{ml} 14 \%$ boron trifluoride-methanol complex. The mixture was brought to $\mathrm{pH} 2$ and left overnight at room temperature. It was then extracted with $0.5 \mathrm{ml}$ chloroform and $3 \mu \mathrm{l}$ samples were injected on to the column. Volatile and non-volatile acids were determined from peak area by reference to a standard curve prepared with known amounts of pure acids.

Protein estimation. This was done by the Lowry method, using bovine serum albumin as standard.

Chemicals. NADH and nitroblue tetrazolium were obtained from Sigma. Bovine serum albumin was obtained from Armour Pharmaceuticals. Eastbourne. Sussex. All other chemicals were analytical reagent grade.

\section{RESULTS AND DISCUSSION}

\section{Cell density}

Cell concentration remained approximately constant at or near complete anaerobiosis. As gas phase $\mathrm{pO}_{2}$ values rose, so the steady-state cell biomass fell. At a $\mathrm{pO}_{2}$ value of $36.7 \mathrm{mmHg}$ the cells began to wash out of the system (Fig. 1).

One generally accepted definition of anaerobiosis is that anaerobes obtain no energetic advantage by the presence of even small amounts of oxygen, and moreover that as the amount of oxygen increases it eventually causes growth inhibition or death. Our experiments with Selenomonas ruminantium WPL 151/1 confirm this view. Increasing the amount of oxygen in the gas phase of a chemostat produced no indication of increasing growth yield, even at very low levels of the acceptor: the cell population fell as the $\mathrm{pO}_{2}$ rose. The observed growth inhibition was not due to the presence of significant amounts of free oxygen, since none could be detected in any experiment using the galvanic probe electrode.

\section{Redox potential and oxygen tension}

The $E_{\mathrm{h}}$ of the uninoculated medium was approximately $-180 \mathrm{mV}$. Increasing the gas phase $\mathrm{pO}_{2}$ from 0 to $36.72 \mathrm{mmHg}$ led to a steady rise in $E_{\mathrm{h}}$ values from $-180 \mathrm{mV}$ to $+94 \mathrm{mV}$. At the latter oxygen tension cells began to wash out of the vessel. A slight plateau near $-40 \mathrm{mV}$ suggested the presence of an unidentified redox couple acting as a poising agent (Fig. 1). Redox potential measurements are not well understood and it is not clear that they are measuring oxygen directly in the culture vessel. They do, however, provide a useful measurement of oxidizing or reducing conditions over a region where free oxygen cannot otherwise be measured (Wimpenny \& Necklen, 1971).

\section{Oxygen consumption and enzyme activities}

Oxygen uptake rates were measured in whole-cell suspensions of $S$. ruminantium WPL 151/1 taken from cultures exposed to different oxygen partial pressures. Both the endogenous and the glucose-stimulated oxygen uptake rates increased sharply to a maximum at a $\mathrm{pO}_{2}$ value of $15 \mathrm{mmHg}$. Above this $\mathrm{pO}_{2}$, both rates declined steadily. Soluble NADH oxidase activity increased on exposing the growing culture to oxygen and also reached a maximum value at a $\mathrm{pO}_{2}$ value of $15 \mathrm{mmHg}$ (Fig. 2). This increase in $\mathrm{NADH}$ oxidase activity took place over a range of culture $E_{\mathrm{h}}$ values from $-180 \mathrm{mV}$ to $0 \mathrm{mV}$ and the maximum value was about seven times the activity of the anaerobically grown culture. With increasing $\mathrm{pO}_{2}$ above $15 \mathrm{mmHg}$, NADH oxidase activity fell, although even at the highest $\mathrm{pO}_{2}$ values examined NADH oxidase was still active. No NADH peroxidase or catalase activities were ever observed.

Oxygen-reducing activity was clearly associated with the appearance in cell extracts of the soluble NADH oxidase. This is almost certainly a flavoprotein oxidase (Dolin, 1962) which is responsible for respiration by whole cells and is probably fuelled by reducing equivalents generated through glycolysis. The anaerobe appears to respond to increasing oxygen tensions by attempting to reduce the oxygen to water or hydrogen peroxide. NADH oxidase activity was shown to increase in response to oxygen in various species of clostridia (O'Brien \& Morris, 1971; Ashley \& Shoesmith, 1977), in batch cultures of S. ruminantium (Wimpenny \& 


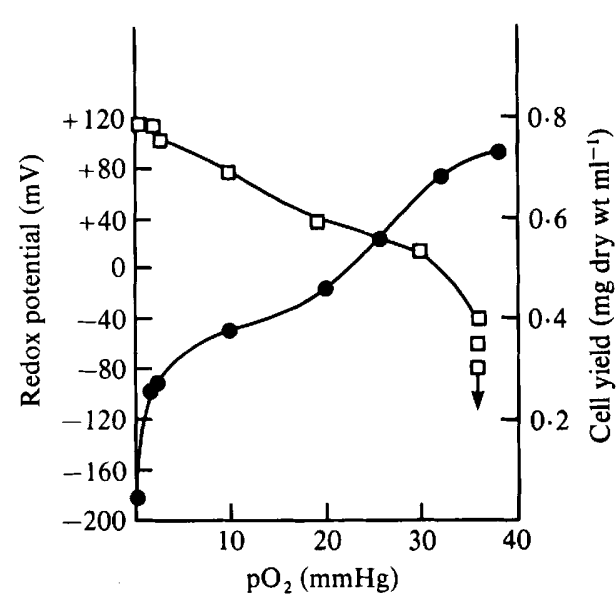

Fig. 1

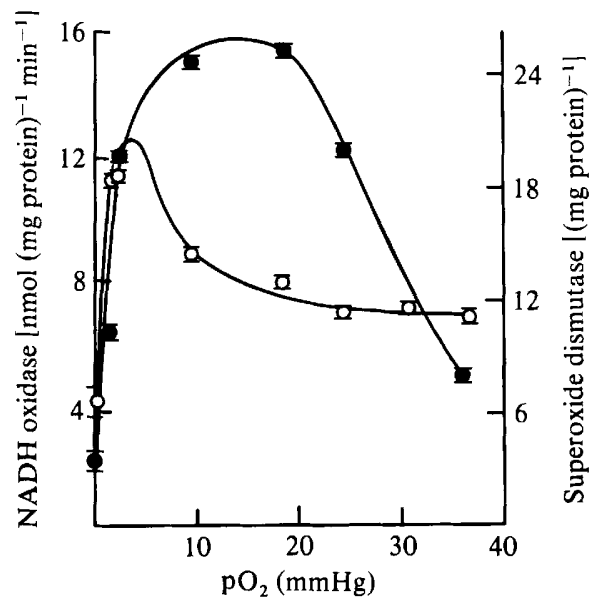

Fig. 2

Fig. 1. The relationship between oxygen partial pressure and cell yield $(\square)$ and redox potential (O) in chemostat cultures of $S$. ruminantium WPL 151/1. Each point represents the mean of three observations.

Fig. 2. Enzyme activities in extracts from $S$. ruminantium WPL $151 / 1$ in chemostat cultures. $O$, Superoxide dismutase (plotted as the reciprocal of the amount of protein to give $50 \%$ inhibition of nitroblue tetrazolium reduction); 1 NADH oxidase. Means of three separate determinations are plotted, with standard deviations shown.

Samah, 1978) and in Peptostreptococcus anaerobius (Hoshino et al., 1978). The organism studied here did not possess a separate NADH peroxidase since the addition of hydrogen peroxide to the NADH oxidase assay did not lead to an increase in the rate of NADH oxidation.

The activity of superoxide dismutase rose to a maximum between $\mathrm{pO}_{2}$ values of 1 and $4 \mathrm{mmHg}$ (Fig. 2). The maximum value recorded was about three to four times the anaerobic figure. At higher $\mathrm{pO}_{2}$ values the activity of superoxide dismutase declined. The responses of superoxide dismutase and of NADH oxidase to oxygen are not the same: the latter curves more gently to a maximum at a higher aeration level than the former. McCord et al. (1971) proposed an interesting explanation for obligate anaerobiosis based on the absence in strict anaerobes of superoxide dismutase. It was later shown by Hewitt \& Morris (1975), Ashley \& Shoesmith (1977) and Wimpenny \& Samah (1978) that many anaerobes do possess this enzyme, and that some species respond to elevated oxygen tensions by increasing its activity (Tally et al., 1977). Such an increase in superoxide dismutase activity occurred in batch cultures of $S$. ruminantium 17 (Wimpenny \& Samah, 1978) and is confirmed here for continuous cultures of the related strain WPL $151 / 1$.

\section{Cytochromes}

Reduced minus oxidized difference spectra of whole cells of $S$. ruminantium WPL 151/1, when measured at room temperature, showed cytochrome $b$ with an $\alpha$ band at $558 \mathrm{~nm}$ and a $\beta$ band at $530 \mathrm{~nm}$. CO-binding pigments were present in anaerobic cells at each gas phase oxygen tension examined. Changes in the concentrations of cytochromes $b$ and $o$ as a function of $\mathrm{pO}_{2}$ are shown in Fig. 3. These cytochromes were at their lowest concentration between 1 and $2 \mathrm{mmHg} \mathrm{pO}$, increasing in concentration with further increases in $\mathrm{pO}_{2}$.

Cytochrome $b$ is almost certainly associated with fumarate reduction in $S$. ruminantium and similar organisms (Chaix \& Fromageot, 1972; deVries et al., 1972, 1974; Sone, 1972); however, the CO-binding pigment (cytochrome $o$ ) is normally accepted to be a cytochrome 


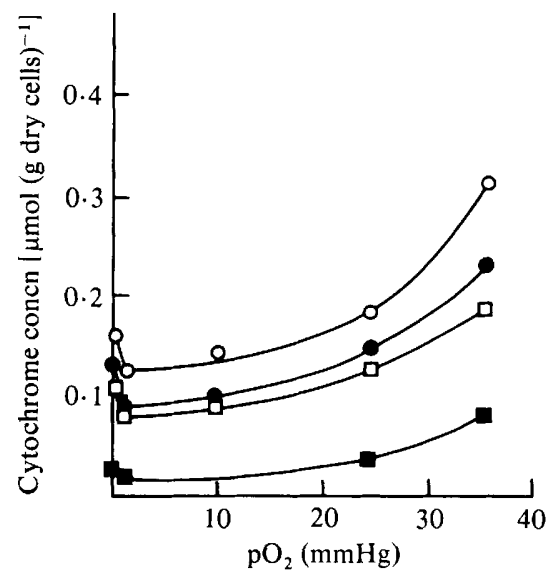

Fig. 3

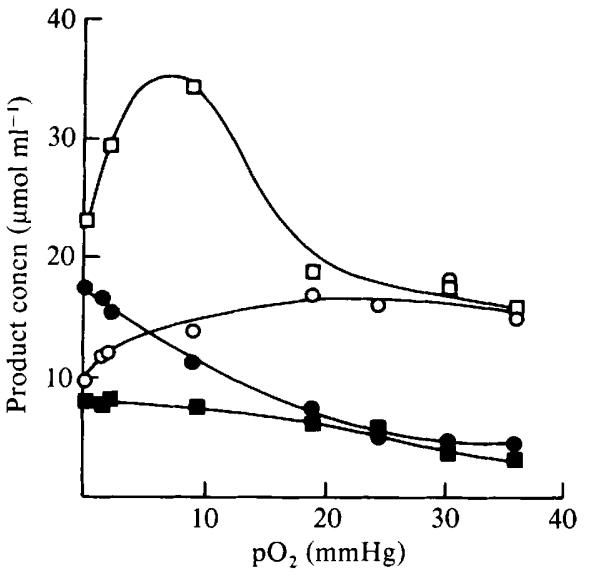

Fig. 4

Fig. 3. Whole-cell cytochrome concentrations as a function of $\mathrm{pO}_{2}$ in chemostat cultures of $S$. ruminantium WPL 151/1: $\mathrm{O}$, cytochrome $b_{558}$ (dithionite-reduced minus ferricyanide-oxidized); $\mathbf{O}$, cytochrome $b_{558}$ (dithionite-reduced minus fumarate-oxidized); $\square$, cytochrome $b_{558}$ (untreated minus fumarate-oxidized); $\boldsymbol{\square}, \mathrm{CO}$-binding pigment. Each point represents the mean of two determinations.

Fig. 4. Steady-state values for the production of acetate $(O)$, propionate $(\bigcirc)$, lactate $(\square)$ and succinate $(\square)$ in chemostat cultures of $S$. ruminantium WPL 151/1. Each point represents the mean of three samples.

oxidase. Some spectra suggested that there were even cytochromes of the $a$ type, which are also recognized as cytochrome oxidases in other bacteria. The possibility that these membrane-bound cytochromes were involved in oxygen consumption was not examined. Their appearance did not correlate with the overall oxygen consumption activity of the organism, since these pigments were present in highest amounts at $\mathrm{pO}_{2}$ values where the cells were washing out of the vessel and oxygen consumption was strongly inhibited.

\section{Fermentation products}

Selenomonas ruminantium WPL 151/1 produced acetate, propionate, lactate and succinate in continuous culture experiments. The amounts of these fermentation products varied according to the $\mathrm{pO}_{2}$ (Fig. 4). Succinate production fell slowly and propionate more steeply as the $\mathrm{pO}_{2}$ increased. Lactate increased to a maximum value at a $\mathrm{pO}_{2}$ near $10 \mathrm{mmHg}$, falling as the $\mathrm{pO}_{2}$ was increased above this value. The most oxidized product, acetate, increased to a maximum at a $\mathrm{pO}_{2}$ of about $30 \mathrm{mmHg}$ before falling slightly when the cells were washing out.

One consequence of enhanced oxygen consumption as a protective device is that it diverts reductant from normal physiological channels to the reduction of oxygen. This was clearly reflected by analysis of fermentation products. The more reduced products, succinate and propionate, fell as the $\mathrm{pO}_{2}$ rose. Lactate increased substantially before falling at higher $\mathrm{pO}_{2}$ values, whilst acetate concentrations increased steadily as conditions became more oxidizing. Pyruvate was not measured in these experiments.

\section{Conclusions}

The responses of Selenomonas ruminantium to oxygen could be as follows: oxygen entering the immediate vicinity of the organism leads to the induction of a soluble NADH oxidase activity which reduces the oxidant to water or hydrogen peroxide. One by-product of this reaction is the toxic superoxide anion (Morris, 1975). The latter specifically induces the enzyme superoxide dismutase which catalyses the transfer of an electron from one superoxide 
anion to a second, generating oxygen and hydrogen peroxide. Oxygen reduction draws reductant from intermediary metabolism, including biosynthesis. This is reflected by the make-up of the fermentation products, which become more oxidized. Oxygen toxicity is expressed as growth inhibition, due to a scarcity in reductant on the one hand and to specific effects such as the oxidation of labile molecules on the other. Products of oxygen reduction such as superoxide and hydrogen peroxide may also accumulate, causing more cell damage.

The authors would like to thank Dr R. W. Lovitt for his help and advice on gas-liquid chromatography and the University of Agriculture Malaysia for providing a staff training scheme.

\section{REFERENCES}

Ashley, N. V. \& Shoesmith, J. G. (1977). Continuous culture of Clostridium sporogenes and Clostridium bifermentans in the presence of oxygen. Proceedings of the Society for General Microbiology $4,144$.

Beauchamp, C. \& Fridovich, T. (1971). Superoxide dismutase: improved assays and an assay applicable to acrylamide gel. Analytical Biochemistry 44, 276-287.

Chaix, P. \& Fromageot, C. (1972). Les cytochromes de Propionibacterium pentosaceum. Bulletin de la Société de chimie biologique 24, 11251127.

DANIEL, R. M. (1970). The electron-transport system of Acetobacter suboxydans with particular reference to cytochromes $o$. Biochimica et biophysica acta 216, 328-341.

DoliN, M. I. (1961). Cytochrome-independent electron transport enzymes in bacteria. In The Bacteria, Volume 2, Metabolism, pp. 425-460. Edited by I. C. Gunsalus \& R. Y. Stanier. New York: Academic Press.

Frölander, F. \& CARLsSon, J. (1977). Bactericidal effect of anaerobic broth exposed to atmospheric oxygen tested on Peptostreptococcus anaerobius. Journal of Clinical Microbiology 6, 117-123.

HewitT, J. \& Morris, J. G. (1975). Superoxide dismutase in obligately anaerobic bacteria. FEBS Letters 50, 315-318.

Hoshino, E., Frölander, R. \& Carlsson, J. (1978). Oxygen and the metabolism of Peptostreptococcus anaerobius VPI4330-1. Journal of General Microbiology 107, 235-248.

Hughes, D. E. (1951). A press for disrupting bacteria and other microorganisms. British Journal of Experimental Pathologv 32, 97-109.

McCord, J. M., Kelle, B. B., JR \& Fridovich, I. (1971). An enzyme-based theory of obligate anaerobiosis, the physiological function of superoxide dismutase. Proceedings of the National Academy of Sciences of the United States of America 68 , 1024-1027.

MORRIS, J. G. (1970). The biochemical basis of oxygen toxicity. Proceedings of the Society for General Microbiology 60, iii.

MorRIs, J. G. (1975). The physiology of obligate anaerobiosis. Advances in Microbial Physiology 12 , 169-246.

Morris, J. G. (1976). Oxygen and the obligate anaerobe. Journal of Applied Bacteriology 40, 229-244.

O'Brien, R. W. \& Morris, J. G. (1971). Oxygen and the growth and metabolism of Clostridium acetobutylicum. Journal of General Microbiology 68, $307-318$.

Ohnishi, T., Kroger, A., Heldt, H. W., Pfaff, E. \& KlingenberG, M. (1967). The response of the respiratory chain and adenine nucleotide system to oxidative phosphorylation in yeast mitochondria. European Journal of Biochemistry 1, 301-311.

Onderdonk, A. B., Johnston, J., Mayhew, J. W. \& GoRBACH, S. L. (1976). Effect of dissolved oxygen and $E_{\mathrm{h}}$ on Bacteroides fragilis during continuous culture. Applied and Environmental Microbiology 31, 168-172.

SONE, N. (1972). The redox reactions in propionic acid fermentation. I. Occurrence and nature of electron transfer system in Propionibacterium arabinosum. Journal of Biochemistry 71, 931-940.

TALLY, F. P., Goldin, B. R., JacoBus, N. V. \& GoRbaCH, S. L. (1977). Superoxide dismutases in anaerobic bacteria of clinical significance. Infection and Immunity 16, 20-25.

UESUGI, I. \& Y AJIMA, M. (1978). Oxygen and strictly anaerobic intestinal bacteria. 1. Effects of dissolved oxygen on growth. Zeitschrift für allgemeine Mikrobiologie 18, 287-295.

DeVries, W., VAN WiJck-Kapteyn, W. M. C. \& STOUTHAMER, A. H. (1972). Influence of oxygen on growth, cytochrome synthesis and fermentation pattern in propionic acid bacteria. Journal of General Microbiology 71, 515-524.

DeVries, W., van WiJck-Kapteyn, W. M. C. \& Oosterhuis, S. K. H. (1974). The presence and function of cytochromes in Selenomonas ruminantium, Anaerovibrio lipolytica and Veillonella alcalescens. Journal of General Microbiology 81, 69-78.

WimpenNy, J. W. T. \& SAMAH, O. A. (1978). Some effects of oxygen on the growth and physiology of Selenomonas ruminantium. Journal of General Microbiology 108, 329--332.

Wimpenny, J. W. T. \& Necklen, D. K. (1971). The redox environment and microbial physiology. 1. The transition from anaerobiosis to aerobiosis in continuous cultures of facultative bacteria. Biochimica et biophysica acta 253, 352-359. 